\title{
Aceite de matico (Piper aduncum) en el control de Moniliophthora roreri agente causal de la moniliasis en cacao
}

\author{
Matico oil (Piper aduncum) in the control of Moniliophthora roreri causal agent of cocoa \\ moniliasis
}

\section{J. Huaman ${ }^{1,2}$ \& O. E. Cabezas ${ }^{1}$}

\begin{abstract}
Resumen
Objetivos: Evaluar a nivel in vitro el efecto del aceite de matico (Piper aduncum) extraído de brotes, hojas e inflorescencia sobre el crecimiento micelial de Moniliophthora roreri. Metodología: Se utilizó el diseño completamente al azar con nueve tratamientos más un testigo adicional. Los tratamientos fueron el resultado de la combinación de los factores lugar de extracción del aceite de matico (brotes, hojas e inflorescencias) y volúmenes de aplicación (11, 15 y $30 \mu \mathrm{L}$ ). Cada tratamiento tuvo tres repeticiones. Sobre cultivos puros de cinco días de crecimiento de $M$. roreri en medio papa dextrosa agar (PDA), colocados en extremos equidistantes de discos de papel de 0,6;0,8 y 1,1 cm de diámetro, se hicieron las aplicaciones de los tratamientos. Se evaluaron el ritmo de crecimiento micelial y el porcentaje de inhibición del crecimiento micelial. Resultados: Los aceites extraídos de los brotes, hojas e inflorescencias reducen el ritmo de crecimiento del M. roreri en comparación al testigo. Del mismo modo, las aplicaciones de los volúmenes de 15 y $30 \mu \mathrm{L}$ inhiben el crecimiento micelial del hongo. Conclusiones: Los aceites extraídos de P. aduncum presentaron bajo condiciones de laboratorio, un efecto de reducción e inhibición en el desarrollo del hongo $M$. roreri, pudiendo ser una buena alternativa para el control de este patógeno.
\end{abstract}

Palabras claves: Piper aduncum, Moniliophthora roreri, aceite esencial, moniliasis, hidrodestilación

\begin{abstract}
Objectives: To evaluate the in vitro effect of matico oil (Piper aduncum) extracted from shoots, leaves, and inflorescence, on the mycelial growth of Moniliophthora roreri. Methodology: The completely randomized design with nine treatments plus an additional control was used. The treatments were the result of the combination of the factors of matico oil extraction location (buds, leaves and inflorescences) and application volumes $(11,15$ and $30 \mu \mathrm{L})$. Each treatment had three repetitions. On pure cultures of five days of growth of $M$. roreri in potato dextrose agar medium (PDA), placed on equidistant ends paper discs of $0.6 ; 0.8$ and $1.1 \mathrm{~cm}$ in diameter, the applications of the treatments were made. The rate of mycelial growth and the percentage of inhibition of mycelial growth were evaluated. Results: The oils extracted from the buds, leaves and inflorescences reduced the growth rate of $M$. roreri compared to the control in application doses between 15 and $30 \mu \mathrm{L}$, inhibiting the mycelial growth of the fungus.Conclusions: The oils extracted from P. aduncum presented, under laboratory conditions, a reduction and inhibition effect on the development of the $M$. roreri fungus, which could be a good alternative for the control of this pathogen.
\end{abstract}

Keywords: Piper aduncum, Moniliophthora roreri, essential oil, moniliasis, hydrodistillation

\footnotetext{
${ }^{1}$ Universidad Nacional Agraria de la Selva, Huánuco, Perú.

${ }_{2}^{2}$ Autor para correspondencia: ciarajhv@gmail.com
} 


\section{Introducción}

La producción de granos de cacao (Theobroma cacao L.) representa para el Perú una fuente importante de divisas, en la exportación orgánica de este producto, ocupa el segundo lugar después de República Dominicana (Ministerio de Comercio Exterior y Turismo, 2016). Se estima que el área de cultivo de cacao en el Perú es de aproximadamente 170 mil hectáreas con un rendimiento promedio anual de $839,2 \mathrm{~kg} \mathrm{ha}^{-1}$ (Organización de las Naciones Unidas para la Agricultura y la Alimentación, 2017).

La incidencia en aumento de enfermedades e insectos plaga disminuye grandemente la producción de cacao tanto en productores convencionales y orgánicos. Dentro de los paquetes tecnológicos propuestos para los productores orgánicos en el control de enfermedades están el uso de caldos minerales y la aplicación de hongos antagonistas como Trichoderma sp., Sin embargo, su uso no es masivo y sus costos son relativamente altos. La moniliasis del cacao, es una enfermedad causada por el hongo Moniliophthora roreri que infecta únicamente a los frutos, ocasionando más del $30 \%$ de las pérdidas en su producción y se encuentra ampliamente distribuida en las principales zonas cacaoteras del Perú.

Las pérdidas en la producción conllevan a buscar nuevas alternativas que tengan bajo impacto ambiental, que sean efectivas y biodegradables. Los aceites esenciales son ampliamente usados para el control de insectos, hongos patógenos, bacterias y otros de manera eficiente (Parra, 2011; Flores \& Puente, 2016). Piper aduncum L. (fam. Piperaceae) es conocida en la selva peruana como matico, es abundante y ampliamente distribuida, usada medicinalmente por los pobladores rurales.

Parra (2011) demostró la actividad antifúngica de los aceites del género Piper, los cuales inhiben el crecimiento del hongo Fusarium oxysporum $\mathrm{f}$. sp. dianthi. Valadares et al. (2018) reportan una inhibición del $100 \%$ del crecimiento micelial de Sclerotinia sclerotiorum a partir de una dosis de $30 \mu \mathrm{L}$ de aceite de inflorescencias de $P$. aduncum. Por la importancia que presentan estos aceites esenciales como una alternativa más para el control del hongo Moniliophthora roreri se planteó esta investigación con el objetivo de determinar a nivel in vitro, el efecto del aceite Piper aduncum extraídos de brotes, hojas e inflorescencia sobre el crecimiento micelial del hongo.

\section{Metodología}

La presente investigación se llevó a cabo en el laboratorio de Fitopatología de la Facultad de Agronomía de la Universidad Nacional Agraria de la Selva, ubicado en Tingo María, distrito Rupa-Rupa de la Provincia de Leoncio Prado en Huánuco con $9^{\circ} 18^{\prime} 34$ " LS , $75^{\circ} 59^{\prime} 56^{\prime \prime}$ LO y altitud de 660 m.s.n.m.

Se estableció el diseño completamente al azar con nueve tratamientos más un testigo. Los tratamientos fueron, generados a partir de los factores a) lugar de extracción del aceite (hojas, brotes e inflorescencias) y b) dosis (11, 15 y 30 $\mu \mathrm{L})$. Cada tratamiento tuvo tres repeticiones.

Para el desarrollo de la investigación se siguió el siguiente procedimiento:

1.Extracción de aceite esencial: Para la extracción del aceite esencial, se utilizó el método de HD con un equipo tipo Clevenger (Scalvenzi et al., 2016), empleandose $1 \mathrm{~kg}$ de cada tipo de tejido fresco (hoja, brote e inflorescencia). Las muestras fueron cortadas en pequeños trozos y colocadas dentro de un matraz con agua destilada. El matraz fue sometido a fuego continuo y el vapor de agua fue condensado en el sistema de enfriamiento. El aceite arrastrado en el vapor de agua fue separado por la formación de las dos fases por la diferencia de densidades. Se eliminó el agua del aceite adicionando sulfato de sodio para luego filtrarse, y ser vertidos en un frasco ámbar. Los aceites aislados se almacenaron bajo refrigeración hasta su uso.

2. Aislamiento de M. roreri: Se realizó a partir de frutos enfermos de cacao mediante los protocolos descritos por French \& Torres (1982) para el aislamiento y purificación en medio de cultivo agar-papa-dextrosa (APD).

3.Actividad antifúngica de los aceites: Para determinar el efecto de las cantidades de los 
aceites se usó el método de discos de papel (Ramírez, 2013) que consistió en cortar discos de 0,$6 ; 0,8$ y $1,1 \mathrm{~cm}$ de diámetro y luego se determinó el volumen de aceite que los saturaba completamente, siendo estos de 11,15 y $30 \mu \mathrm{L}$ respectivamente. Posteriormente dos discos de cada tamaño de papel fueron colocados equidistantes en cada placa de Petri de $90 \mathrm{~mm}$ de diámetro que contenían el aislamiento puro de $M$. roreri incubados por cinco días antes. En cada placa y en cada tamaño de disco de papel fueron colocados los volúmenes de aceites de hoja, brotes e inflorescencias.

Se evaluaron las siguientes variables:

a) Ritmo de crecimiento (RC): Para determinar el efecto en el crecimiento micelial de $M$. roreri las evaluaciones se realizaron cada 24 horas por 6 días. Se calculó mediante la siguiente fórmula:

$$
\mathrm{RC}=\mathrm{IC} / \mathrm{TT}
$$

RC: ritmo de crecimiento; IC: incrmento total (cm); TT: tiempo total (días)

b) Porcentaje de inhibición del crecimiento micelial (\% ICM): Al igual que la anterior, las evaluaciones se realizaron cada 24 horas por 6 días. Se calculó mediante la siguiente fórmula:

$\% \mathrm{ICM}=\frac{(\text { Crecimiento testigo }- \text { Crecimiento tratamiento })}{\text { Crecimiento testigo }} \times 100$

De las dos variables, solo el ritmo de crecimiento (RC) fue sometido a análisis de variancia (ANOVA), utilizándose para la comparación de medias la prueba de Duncan $(\alpha=0,05)$. Los datos fueron procesados con el software InfoStat.

\section{Resultados y discusión}

Los aceites extraídos de inflorescencias, brotes y hojas de Piper aduncum no presentaron diferencias a los seis días de evaluación sobre la disminución del ritmo de crecimiento micelial de Moniliophthora roreri, de acuerdo a la prueba de Duncan $(P>0,05)$; sin embargo, los tres tipos de aceite sí resultaron ser altamente significativos frente al testigo (Tabla 1). Estos resultados evidencian que el aceite de matico tiene efecto en la inhibición del crecimiento micelial de $M$. roreri. Los tres aceites en promedio mostraron un crecimiento de $1,3 \mathrm{~cm}$ por día; mientras que en el testigo tuvo un crecimiento de $2,84 \mathrm{~cm}$ por día, lo que significa que el aceite de $P$. aduncum redujo el ritmo de crecimiento de $M$. roreri en un $54,2 \%$ frente al testigo.

Tabla 1

Efecto del aceite de Piper aduncum sobre el crecimiento micelial de M. roreri

\begin{tabular}{lccc}
\hline $\begin{array}{c}\text { Aceite } \\
\text { extraido de: }\end{array}$ & $\begin{array}{c}\text { Ritmo de } \\
\text { crecimiento } \\
\text { micelial } \\
(\mathrm{cm} / \text { día })\end{array}$ & $\begin{array}{c}\text { Ritmo de } \\
\text { crecimiento } \\
\text { medio }\end{array}$ & $\begin{array}{c}\% \text { de } \\
\text { inhibición } \\
\text { frente al } \\
\text { testigo }\end{array}$ \\
\hline Inflorescencia & $1.01^{\mathrm{a}}$ & & \\
Brotes & $1.30^{\mathrm{a}}$ & 1.3 & 54.2 \\
Hojas & $1.61^{\mathrm{a}}$ & & \\
Testigo & $2.84^{\mathrm{b}}$ & & \\
\hline a,b & Tratamientos con distintas letras indican diferencia \\
\multicolumn{2}{l}{ estadistica $(P>0,05)}$.
\end{tabular}

Muchos autores han estudiado la composición química del P. aduncum indicando que el Dilapiol es uno de sus principales compuestos, el que fluctúa dependiendo del lugar geográfico donde se encuentre la planta (Guerrini et al., 2009; Pino et al., 2011); esta actividad antibacteriana del aceite de $P$. aduncum pudo incrementarse como consecuencia del sinergismo de los diversos compuestos que interactúan en la inhibición del hongo; Scalvenzi et al. (2016) también indican que $P$. aduncum es una planta promisoria en el control biológico de hongos fitopatógenos.

En la Figura 1 se muestra el porcentaje de inhibición de los aceites extraídos de Inflorescencia, brotes y hojas en el crecimiento micelial de $M$. roreri, determinando que el aceite de extraído de las inflorescencias posee mayor porcentaje inhibitorio $(64,4 \%)$; mientras que los extraídos de brotes $(54,2 \%)$ y hojas $(43,3 \%)$, es menor.

El análisis estadístico del ritmo de crecimiento micelial entre las tres dosis diferentes, muestran diferencias significativas (Tabla 2). En la comparación realizada se observa que los aceites extraídos de brotes, hojas e inflorescencia tienen un efecto inhibitorio que depende de la dosis empleada. 


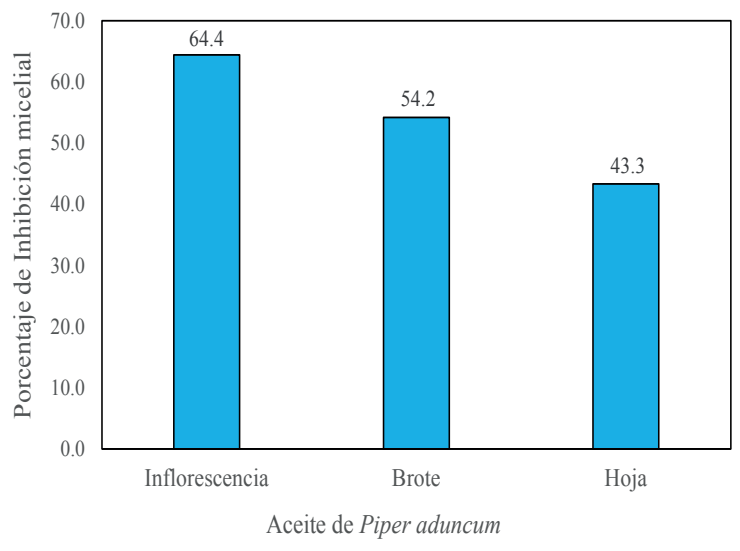

Figura 1. Inhibición del crecimiento micelial (\%) de M. roreri por efecto de aceite de matico.

Las dosis de 15 y $30 \mu \mathrm{L}$ mostraron mejor efecto en el control de crecimiento micelial de M. roreri para los tres aceites extraídos; mientras que la dosis de $11 \mu \mathrm{L}$ mostró un crecimiento igual del hongo entre los aceites de brotes y hojas. Así mismo, se destaca la efectividad del aceite extraído de la inflorescencia como el mejor, donde el valor para todos los tratamientos fue de 0,18. El aceite extraído de las inflorescencias muestra un mayor efecto en la inhibición micelial con las diferentes dosis aplicadas. Baser \& Buchbauer (2010) indican que la composición del aceite esencial también varía de acuerdo al órgano o parte de la planta del cual se extraiga. Estos resultados son evidenciados por Guerrini et al. (2008) que evaluaron la actividad antifúngica del aceite Piper aduncum a diferentes concentraciones, frente al comportamiento de otros hongos fitopatógenos obteniendo resultados positivos en la inhibición del micelio de los hongos a la más alta concentración del aceite.

Tabla 2

Ritmo de crecimiento micelial (cm/dia) bajo diferentes dosis del aceite esencial de matico

\begin{tabular}{cccc}
\hline $\begin{array}{c}\text { Tratamiento } \\
(\mu \mathrm{L})\end{array}$ & Brotes & Hojas & Inflorescencias \\
\hline 11 & $0,36^{\mathrm{b}}$ & $0,36^{\mathrm{b}}$ & $0,18^{\mathrm{a}}$ \\
15 & $0,27^{\mathrm{a}}$ & $0,29^{\mathrm{a}}$ & $0,18^{\mathrm{a}}$ \\
30 & $0,26^{\mathrm{a}}$ & $0,24^{\mathrm{a}}$ & $0,18^{\mathrm{a}}$ \\
\hline a,b & $\begin{array}{l}\text { Valores entre tratamientos con la misma letra en } \\
\text { sentido vertical, no presentan significación estadistica. } \\
(P>0,05) .\end{array}$
\end{tabular}

En la Figura 2 se muestra el porcentaje de inhibición de los aceites extraídos de inflorescencia, brotes y hojas a diferentes dosis de aplicación $(11,15$ y $30 \mu \mathrm{L})$ de $\mathrm{P}$. aduncum sobre el crecimiento micelial del hongo. Se aprecia que el aceite extraído de las inflorescencias, a cualquier dosis de aplicación, obtiene un mayor porcentaje de inhibición $(73,91 \%)$, mientras que los extraídos de hojas y brotes a una dosis de $11 \mu \mathrm{L}$ tuvieron resultado menor $(47.83 \%)$. Investigaciones realizadas por Cabrera \& Yaguache (2015) emplearon aceite de P. aduncum a una dosis de $500 \mu \mathrm{L}$, obteniéndo un $65 \%$ de inhibición en el crecimiento micelial de $M$. roreri, mientras que los resultados obtenidos en esta investigación muestran 73,91 $\%$ de inhibición frente a este hongo en las tres dosis aplicadas por el aceite extraído de inflorescencias.

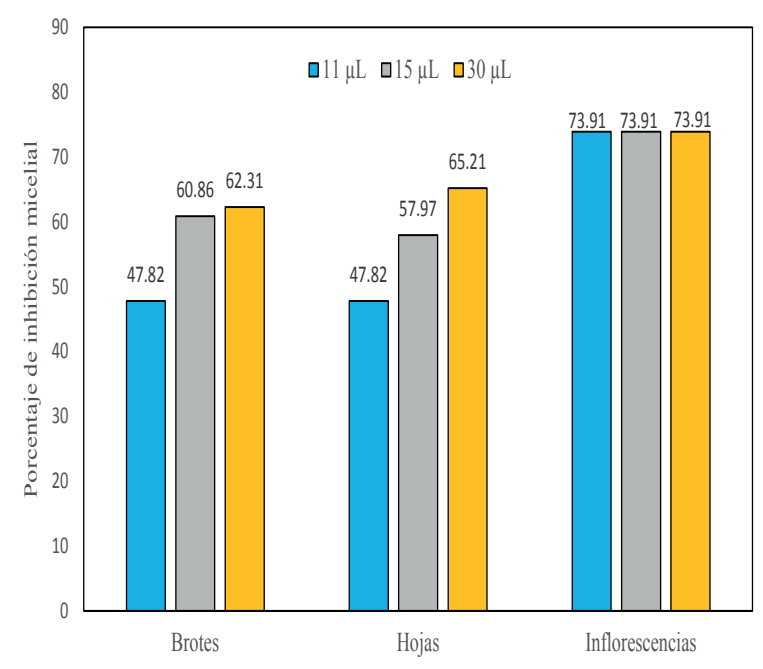

Figura 2. Inhibición del crecimiento micelial (\%) de Moniliophthora roreri bajo diferentes dosis de aceite de P. aduncum.

\section{Conclusión}

El aceite esencial de $P$. aduncum, bajo condiciones de laboratorio, redujo el ritmo de crecimiento del hongo y mostró un efecto inhibidor en el desarrollo del hongo $M$. roreri, especialmente el aceite extraído de las inflorescencias entre las diferentes dosis aplicadas. Estos resultados evidencian una alternativa para la agricultura orgánica en el control biológico de hongos fitopatógenos. 


\section{Referencias}

Baser, K. \& Buchbauer, G. (Ed.). (2010). Handbook of essential oils: science, technology, and applications. Boca ratón, United States of America: CRC Press.

Cabrera, P. F. \& Yaguache, B. D. (2015). Aceites esenciales de plantas amazónicas para el control de fitopatógenos de cultivos convencionales de la provincia de Pastaza (tesis de maestría). Universidad de las Fuerzas Armadas, Sangolqui, Ecuador.

Organización de las Naciones Unidas para la Agricultura y la Alimentación. (2017). FAOSTAT. Disponible en: http://www.fao. org/faostat/en/\#data/QC

Flores, K., \& Puente, M. R. (2016). Actividad antibacteriana del aceite esencial de Piper aduncum "matico" sobre Escherichia coli (tesis de pregrado). Universidad Nacional de los Andes, Huancayo, Perú.

French, E. R. \& Torres H. T.T. (1982). Métodos de investigación fitopatológica, San José, Costa Rica: Instituto Interamericano de Cooperación para la Agricultura (IICA).

Guerrini, A., Sacchetti, G., Rossi, D., Paganetto, G., Muzzoli, M., Andreotti, E. \& Bruni, R. (2009). Bioactivities of Piper aduncum L. and Piper obliquum Ruiz \& Pavon (Piperaceae) essential oils from Eastern Ecuador. Environmental Toxicology and Pharmacology, 27(1), 39-48. doi. org/10.1016/j.etap.2008.08.002

Ministerio de Comercio Exterior y Turismo, (2016). Análisis integral de la logística en el Perú, parte 1: resultados agregados y lineamiento estratégico. Recuperado de: https://www.mincetur.gob.pe/wp-content/ uploads/documentos/comercio_exterior/ facilitacion comercio exterior/Analisis Integral_Logistica_Peru.pdf
Parra, J. E. (2011). Contribución al estudio fotoquímico de la parte aérea de P. cf. cumanense Kunth (Piperacea) (tesis de maestría). Universidad Nacional de Colombia, Bogotá, Colombia.

Pino, O., Sánchez, Y., Rodríguez, H., Correa, T. M., Demedio, J. \& Sanabria, J. L. (2011). Características químicas y actividad acaricida del aceite esencial de Piper aduncum subsp. Ossanum frente a Varroa destructor. Protección Vegetal, 26(1), 5261.

Ramírez, S.I. (2013). Efectividad De Extractos vegetales en el manejo de la moniliasis (Moniliophthora roreri) del cacao (Theobroma cacao L.) en México (tesis doctoral). Universidad Nacional de Costa Rica, Heredia, Costa Rica.

Scalvenzi, L., Yaguache-Camacho, B., CabreraMartinez, P. \& Guerrini, A. (2016). Actividad antifúngica in vitro de aceites esenciales de Ocotea quixos (Lam.) Kosterm. y Piper aduncum L. Bioagro, 28(1), 39-46.

Valadares, A. C. F., Alvares, C. C. F., Alves, J. M., De Deus, I. P. B., De Oliveira, J. G., Dos Santos, T. C.L., Días, H., Crotti, A., \& Miranda, M. (2018). Essential oils from Piper aduncum inflorescences and leaves: chemical composition and antifungal activity against Sclerotinia sclerotiorum. Anais da Academia Brasileira de Ciências, 90(3), 2691-2699. doi.org/10.1590/00013765201820180033 